\title{
Improved ozone profile retrievals from GOME data with degradation correction in reflectance
}

\author{
X. Liu, K. Chance, and T. P. Kurosu \\ Atomic and Molecular Physics Division, Harvard-Smithsonian Center for Astrophysics, Cambridge, MA, USA \\ Received: 22 March 2006 - Published in Atmos. Chem. Phys. Discuss.: 30 August 2006 \\ Revised: 30 January 2007 - Accepted: 22 March 2007 - Published: 23 March 2007
}

\begin{abstract}
We present a simple method to perform degradation correction to Global Ozone Monitoring Experiment (GOME) reflectance spectra by comparing the average reflectance for $60^{\circ} \mathrm{N}-60^{\circ} \mathrm{S}$ with that at the beginning of GOME observations (July-December 1995) after removing the dependences on solar zenith angle and seasonal variation. The results indicate positive biases of up to $\sim 15-25 \%$ in the wavelength range 289-370 nm during 2000-2002; the degradation also exhibits significant dependence on wavelength and viewing zenith angle. These results are consistent with previous studies using radiative transfer models and ozone observations. The degradation causes retrieval biases of up to $\sim 3 \%\left(10 \mathrm{DU}, 1 \mathrm{DU}=2.69 \times 10^{16}\right.$ molecules $\left.\mathrm{cm}^{-2}\right), 30 \%$ (10 DU), $10 \%$, and $40 \%$ in total column ozone, tropospheric column ozone, stratospheric ozone and tropospheric ozone, respectively, from our GOME ozone profile retrieval algorithm. In addition, retrieval biases due to degradation vary significantly with latitude. The application of this degradation correction improves the retrievals relative to Dobson and ozonesonde measurements at Hohenpeißenberg station during 2000-2003 and improves the spatiotemporal consistency of retrieval quality during 1996-2003. However, because this method assumes that the deseasonalized globally-averaged reflectance does not change much with time, retrievals with this correction may be inadequate for trend analysis. In addition, it does not correct for instrument biases that have occurred since launch.
\end{abstract}

\section{Introduction}

The Global Ozone Monitoring Experiment (GOME), launched on board the European Space Agency's (ESA) second Earth Remote Sensing (ERS-2) satellite in April 1995, measures backscattered light from the Earth's atmosphere

Correspondence to: X. Liu

(xliu@cfa.harvard.edu) and surface in the wavelength range $240-790 \mathrm{~nm}$ (ESA, 1995). Observations with spectral resolution of $0.2 \mathrm{~nm}$ and high signal to noise ratio in the Hartley and Huggins bands enable retrieval of the vertical distribution of ozone from $\sim 50 \mathrm{~km}$ down into the troposphere (Chance et al., 1997; Munro et al., 1998; Hoogen et al., 1999; Hasekamp and Landgraf, 2001; van der A et al., 2002; Müller et al., 2003; Liu et al., 2005).

As a follow-on of the GOME instrument, the GOME-2 series has started with the launch of the first Meteorological Operational satellite (MetOp) in October 2006. One of the keys to continuously monitoring the vertical distribution of ozone is ensuring consistent high-quality ozone profiles retrieved from the GOME record. However, GOME has degraded over time because of ultraviolet light damage to its optical elements and contaminants that fill voids in the $\mathrm{MgF}_{2}$ coating of the scan mirror (Snel, 2000). Although a degradation correction is applied in the standard GOME Data Processor extraction software, it is assumed that radiance and irradiance spectra degrade in the same way (i.e., no degradation in the reflectance). However, the scan-mirror degradation due to the change of its reflective properties by contaminants has a strong dependence on the incident angle (Senl, 2000). The degradation differs substantially between the solar irradiances and backscattered radiances, therefore leading to degradation in the reflectance (Snel, 2000; Tanzi et al., 2000; van der A et al., 2002). Without degradation correction in the reflectance after 1998, ozone profile retrievals can be significantly affected or even cannot proceed (van der A et al., 2002). Empirical schemes have been developed to correct the reflectance degradation by comparing measured and simulated reflectance spectra. van der A et al. (2002) derived degradation correction before 2000 using ozone profile climatology and with surface albedo retrieved from measurements at $400 \mathrm{~nm}$. In the Climatology of Height-resolved Earth Ozone and Profiling Systems for GOME (CHEOPSGOME), Krijger et al. (2005) performed a dedicated study to derive GOME reflectance degradation over the GOME

Published by Copernicus GmbH on behalf of the European Geosciences Union. 
lifetime using a combination of ozonesonde observations and climatology. Although these forward model approaches can be used to check both instrument calibration at any time period and instrument degradation, there are several disadvantages. First, due to the uncertainties and inhomogeneous performance of ozonesonde observations, especially in the upper troposphere and lower stratosphere (Liu et al., 2006), the derived correction parameters can vary significantly with latitude or vary from location to location. Second, one has to assume an ozone distribution above the ozonesonde by combining them with different types of measurements (e.g., lidar measurements). This requires careful collocations of all ozone measurements including GOME; however, the number of such triple collocations is very limited. Third, if surface albedo is derived from uncorrected measurements, error in derived surface albedo directly propagates into the simulated spectra, leading to incomplete degradation correction (Krijger et al., 2005). One approach to perform a degradation correction in the spectral region for deriving surface albedo is to use measurements in regions with nearly constant surface albedo and little cloud coverage such as the Libyan Desert (Krijger et al., 2005). Fourth, the forward model approach does not allow one to distinguish between forward model errors and instrument errors.

Our algorithm to retrieve ozone profiles from GOME has been described in detail and validated in a previous paper (Liu et al., 2005). Retrieved ozone profiles are usually consistent with the Stratospheric Aerosol and Gas Experiment II (SAGE-II) ozone profiles to within 15\% during 1996-1999, despite a systematic altitude-dependent bias which exists as a result of the initial offset in GOME channel 1 (van der A et al., 2002; Krijger et al., 2005). The retrieved total column ozone (TO) and tropospheric column ozone (TCO) agrees well with Total Ozone Mapping Spectrometer (TOMS), Dobson and ozonesonde measurements to within $6 \mathrm{DU}\left(2 \%, 1 \mathrm{DU}=2.69 \times 10^{16}\right.$ molecules $\left.\mathrm{cm}^{-2}\right)$ and 3 DU (15\%), respectively. Our retrieval algorithm corrects part of the degradation by fitting a 2nd-order polynomial in the spectral region 289-307 $\mathrm{nm}$ and a wavelength-dependent surface albedo (2nd-order polynomial) in the wavelength region $326-339 \mathrm{~nm}$. These correctiosn enables ozone profile retrievals to proceed for all measurement periods; otherwise, retrievals are often unsuccessful during 2000-2003 due to negative ozone values caused by the degradation. However, the quality of the retrievals, especially the tropospheric ozone, has degraded significantly since 2000 . A degradation correction is necessary to make the retrieval performance consistent for all periods.

This study presents an alternative and simple degradation correction scheme for GOME measurements without using radiative transfer models and climatological/observed ozone profiles. We demonstrate that this scheme can greatly improve the spatiotemporal consistency of retrievals especially in the troposphere for the GOME record.

\section{Degradation correction scheme}

The degradation on a certain day and at a particular wavelength is derived from the ratios of reflectance $\left(I /\left(F \cos \theta_{0}\right)\right.$, where $I$ is the radiance, $F$ is the irradiance, and $\theta_{0}$ is the solar zenith angle) averaged over all longitudes between $60^{\circ} \mathrm{N}-$ $60^{\circ} \mathrm{S}$ to that on 1 July 1995 (the average reflectance in JulyDecember 1995 is used as the final reference). The underlying assumption is that the deseasonalized global average reflectance does not change in time. A similar approach was used to perform degradation correction for GOME irradiances (http://wdc.dlr.de/sensors/gome/degradation_files/ degradation.html). However, unlike the irradiance, the reflectance depends strongly on atmospheric conditions (e.g., clouds, aerosols, absorbers, surface albedo) and viewing geometry. So we need to average data spatiotemporally to reduce the effect of atmospheric variability. According to the International Satellite Cloud Climatology Project radiative Flux Data (ISCCP-FD), the largest differences in the deseasonalized monthly mean planetary albedo are within $2 \%$ during the GOME life time to date (http://isccp.giss.nasa.gov/ projects/browse_fc.html). The ISCCP-FD data also illustrate that the fluctuations in the reflected shortwave radiation averaged in the tropics are larger than that averaged over the globe which is related to El Niño processes (Gupta et al., 2006). Therefore, to derive the large degradation in GOME data, which can be larger than $20 \%$ (Krijger et al., 2005), it is generally valid to assume a relatively invariant global average reflectance. Due to the lack of solar-illumination at high latitudes in some seasons, we average the reflectance over $60^{\circ} \mathrm{N}-60^{\circ} \mathrm{S}$ (excluding the South Atlantic Anomaly region).

Figure 1a (purple line) shows an example at $331 \mathrm{~nm}$ of the calculated ratios for nadir pixels starting from 1 July 1995 to 1 June 2003 (using the first and middle day of each month). Data after this period are excluded because the failure of the onboard tape recorder for intermediate data storage leads to limited spatial coverage. This curve clearly shows annual variations and short-term fluctuations superimposed over the long-term variation. These variations are primarily caused by the variation of average solar zenith angle (black line), the seasonal variation of atmospheric conditions, and the shortterm atmospheric variation. We use non-linear least squares fitting to remove the components related to solar zenith angle (a 3rd-order polynomial of the cosine of solar zenith angle) and seasonal variation (a 3rd-order polynomial of the time within a year). We normalize the derived ratios to the average ratio over July-December 1995 and then apply a two-month running mean, which reduces the dependence on short-term atmospheric variability. The derived curve of reflectance degradation for nadir pixels (light blue in Fig. 1a) shows little degradation until late 1999 and afterwards a positive bias gradually increases, peaks at 1.18 in May 2001, gradually returns to normal, and then changes sign. Figure 1a also illustrates that degradation varies significantly with scan position, with the peak degradation ranging from 1.07 for 

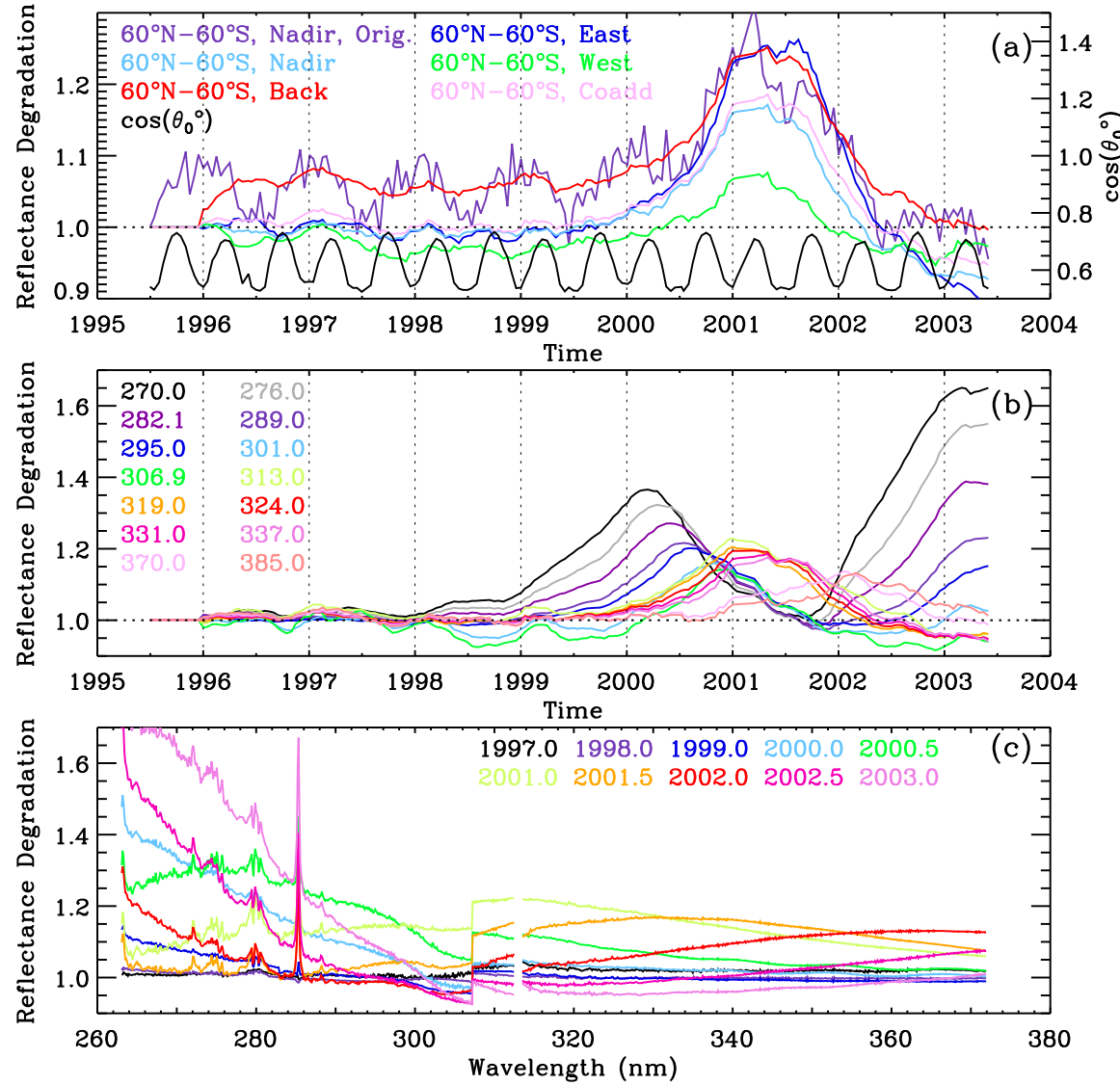

Fig. 1. (a) Derived degradation in reflectance at $331 \mathrm{~nm}$ for different scan positions and additionally the average solar zenith angle vs. time. "Orig." means the ratios of average reflectance to that on 1 July 1995 and "coadd" refers to the derived degradation of the reflectance averaged from four scan positions. (b) Degradation (co-added) vs. time for selected wavelengths. (c) Degradation (co-added) vs. wavelength for selected times.

the West pixel to 1.25 for the East pixel. The degradation curve and its scan-angle dependence is consistent with the prediction of Snel (2000), which is based on physical understanding of how the depth of contaminants on the scan mirror affects the reflectance. The degradation patterns and their magnitudes for different positions agree very well with the derived degradation using a forward model approach by Krijger et al. (2005). For example, their derived degradation values at $325 \mathrm{~nm}$ are $\sim 1.30,1.18$, and 1.10 for the East, nadir, and West pixels, respectively.

In our retrievals, we co-add eight channel $1 \mathrm{~b}$ and $2 \mathrm{~b}$ pixels (i.e., two cycles of east, nadir, west and back-scan pixels, each of which is integrated over $1.5 \mathrm{~s}$ ) to match the corresponding channel 1a pixel (i.e., integrated over $12 \mathrm{~s}$ ). Accordingly, we derive the degradation for GOME channel 1a from its reflectance and derive the degradation for the coadded spectral region from the co-added reflectance. Figure 1a (pink line) shows the degradation curve for the coadded reflectance at $331 \mathrm{~nm}$. Its magnitude is close to that for the nadir position with a peak value of $\sim 1.19$ in May 2001 .
The channel $1 \mathrm{a} / 1 \mathrm{~b}$ boundary was changed from $307 \mathrm{~nm}$ to $283 \mathrm{~nm}$ on 6 June 1998; the spectral region $283-307 \mathrm{~nm}$ is integrated over $12 \mathrm{~s}$ and $1.5 \mathrm{~s}$ before and after the change, respectively. Correspondingly, we use the reflectance integrated over $12 \mathrm{~s}$ and the co-added reflectance before and after the change, respectively.

Figure $1 \mathrm{~b}$ demonstrates that the degradation behaviors are different at various wavelengths especially after 2000 and Fig. 1c clearly shows significant wavelength dependence for different time periods. The main characteristics are very consistent with the results of Krijger et al. (2005). Both show the forward shift of maximal degradation with increasing wavelengths and second peaks in early 2003 for shorter wavelengths. For example, at $270 \mathrm{~nm}$, both show a first maximal value of $\sim 1.34$ in February-April 2000 and a second maximal value of $\sim 1.60$ in April-May 2003; at $324 \mathrm{~nm}$, both show maximal degradation of $\sim 1.19$ in February-March 2001. In addition, both show a strong spike around $285 \mathrm{~nm}$ (Fig. 1c), which generally increases with degradation. This spike is the result of the $\mathrm{Mg}$ absorption line and very weak 
Table 1. Comparison statistics (Mean bias in DU, $1 \sigma$ standard deviation in DU, and correlation coefficient) between GOME retrievals (without and with degradation correction) around Hohenpeißenberg with coincident Dobson total column ozone (TO) and ozonesonde tropospheric column ozone (TCO) for the whole period, 1996-2000 when degradation is less significant, and other selected periods with large degradation.

\begin{tabular}{llllllll}
\hline & \multicolumn{3}{l}{ Time Periods } & \multicolumn{3}{c}{ Without Correction } & \multicolumn{3}{c}{ With Correction } \\
\hline \multirow{4}{*}{ TO } & $01 / 1996-05 / 2003$ & 1.8 & 12.0 & 0.95 & 2.4 & 11.9 & 0.95 \\
& $01 / 1996-12 / 1999$ & 2.7 & 12.3 & 0.95 & 2.7 & 12.3 & 0.94 \\
& 2000 & 0.3 & 12.3 & 0.92 & 2.1 & 11.6 & 0.93 \\
& 2001 & -5.2 & 11.2 & 0.95 & -0.7 & 11.4 & 0.95 \\
& $01 / 2000-05 / 2003$ & 0.7 & 12.0 & 0.95 & 2.2 & 11.8 & 0.95 \\
\hline \multirow{4}{*}{ TCO } & $01 / 1996-05 / 2003$ & -0.3 & 5.9 & 0.56 & -0.1 & 5.5 & 0.62 \\
& $01 / 1996-12 / 1999$ & 0.0 & 5.7 & 0.60 & -0.2 & 5.6 & 0.60 \\
& 2000 & -1.3 & 5.0 & 0.62 & 0.6 & 4.4 & 0.71 \\
& 2001 & -5.2 & 6.9 & 0.30 & 0.1 & 6.3 & 0.51 \\
& $01 / 2000-05 / 2003$ & -0.9 & 6.2 & 0.53 & -0.1 & 5.2 & 0.64 \\
\hline
\end{tabular}

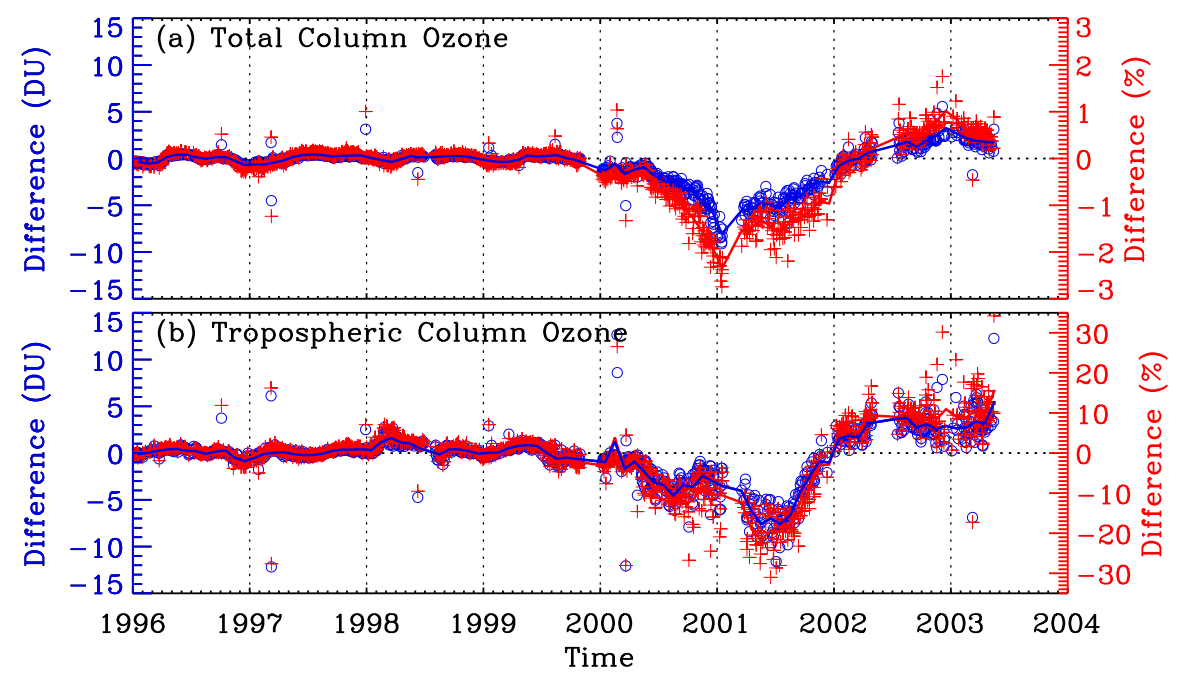

Fig. 2. Absolute (blue) and percent (red) differences in retrieved (a) total column ozone and (b) tropospheric column ozone ("without degradation correction" minus “with degradation correction”) around Hohenpeißenberg (11.0 E, 47.8 ${ }^{\circ}$ N) from 1996 through May 2003.The symbols and lines indicate individual and monthly mean differences, respectively.

radiance signal in this wavelength (Krijger et al., 2005). One main difference occurs at $385 \mathrm{~nm}$; our degradation curve shows a maximal value of 1.13 in February 2002, while their degradation curve shows a broad maximum of $\sim 1.09$ during 2002-2003. van der A et al. (2002) showed degradation only up to early 2000 before significant degradation starts for longer wavelengths. At shorter wavelengths, their results usually show larger degradation in early 2000 . For example, the degradation is $\sim 1.16$ at $289 \mathrm{~nm}, 6 \%$ and $4 \%$ larger than the values in this study and in Krijger et al. (2005), respectively. During the period when we expect no degradation (i.e., before 1998), we still see slight annual variations. However, the values are generally within $\pm 3 \%$. At 301 and
$307 \mathrm{~nm}$, there are stronger seasonal variations during 19961999 with negative degradation of up to $7 \%$. The results of Krijger et al. (2005) also show variations of similar magnitudes before 1998. They also show similar variations for 301 and $307 \mathrm{~nm}$ during 1998 and 1999; but the results of van der A et al. (2002) show opposite degradation between 300$307 \mathrm{~nm}$. These variations are likely due to non-seasonal variations of atmospheric conditions including ozone. It should be noted that there is a jump around $307 \mathrm{~nm}$ (i.e., channel 1a/1b border before June 1998), 2-4\% before June 1998 and 6-8\% after 1998. The results of van der A et al. (2002) also show such a jump, but their results are smoothed over the spectral domain. This jump before June 1998 is related to the 
radiance jump above $307 \mathrm{~nm}$ in March 1996, when the integration time of channels $1 \mathrm{~b}$ to 4 was changed from $0.375 \mathrm{~s}$ to $1.5 \mathrm{~s}$. The change of channel $1 \mathrm{a} / 1 \mathrm{~b}$ boundary from $307 \mathrm{~nm}$ to $283 \mathrm{~nm}$ in June 1998 increased this jump. Note that this jump does not cause problems in our retrievals, because we do not use $307-325 \mathrm{~nm}$ in our retrievals. For algorithms using both spectral regions, special caution is required to deal with this reflectance jump.

We tried using GOME data averaged in other latitude ranges (i.e., $60^{\circ} \mathrm{N}-30^{\circ} \mathrm{N}, 15^{\circ} \mathrm{N}-15^{\circ} \mathrm{S}$, and $30^{\circ} \mathrm{S}-60^{\circ} \mathrm{S}$ ) or averaged in other ranges of brightness (i.e., 20\% darkest and $20 \%$ brightest), and we found that using all GOME data averaged over $60^{\circ} \mathrm{N}-60^{\circ} \mathrm{S}$ better reduces the effect of atmospheric variability, leading to less oscillations before 1998 , when the degradation is insignificant. The initial reference period (July-December 1995) and the length of the running mean ( 2 months) are empirically selected. They minimally affect the results; the degradation changes are within $1.5 \%$ when changing the reference period by 3 months and the length of running mean by 1 month.

To apply the degradation correction to our ozone profile retrieval algorithm (Liu et al., 2005), we parameterize the degradation as a function of wavelength (3rd-order polynomial) over the two fitting windows (289-307 nm, 325$339 \mathrm{~nm}$ ) separately and calculate the average degradation over $368-372 \mathrm{~nm}$, which is used to derive cloud fraction for the subsequent retrievals. The purpose of this parameterization is to remove the high-frequency structures shown in Fig. 1c, which can interfere with ozone retrievals and largely increase fitting residuals. To perform degradation correction in retrievals for a particular time period, we multiply the parameterized wavelength-dependent degradation at that time with the corresponding solar spectra before retrievals start.

This degradation scheme is simpler than other approaches (van der A et al., 2002; Krijger et al., 2005). It does not require the use of radiative transfer models and observed/climatological ozone profiles. In addition, the correction can be performed over non-ozone absorbing wavelength ranges. This method can be used to detect major degradation features in reflectance and to cross-calibrate observations from different instruments. However, because this correction assumes that the globally-averaged radiation fields do not change over time, retrievals with this derived degradation correction may be inadequate for trend analysis. van der A et al. (2001) and Krijger et al. (2005) identified an overestimation of $\sim 10 \%$ in reflectance below $300 \mathrm{~nm}$ that has occurred since launch. Because our method uses measurements at launch as a reference, it could not correct those instrumental errors.

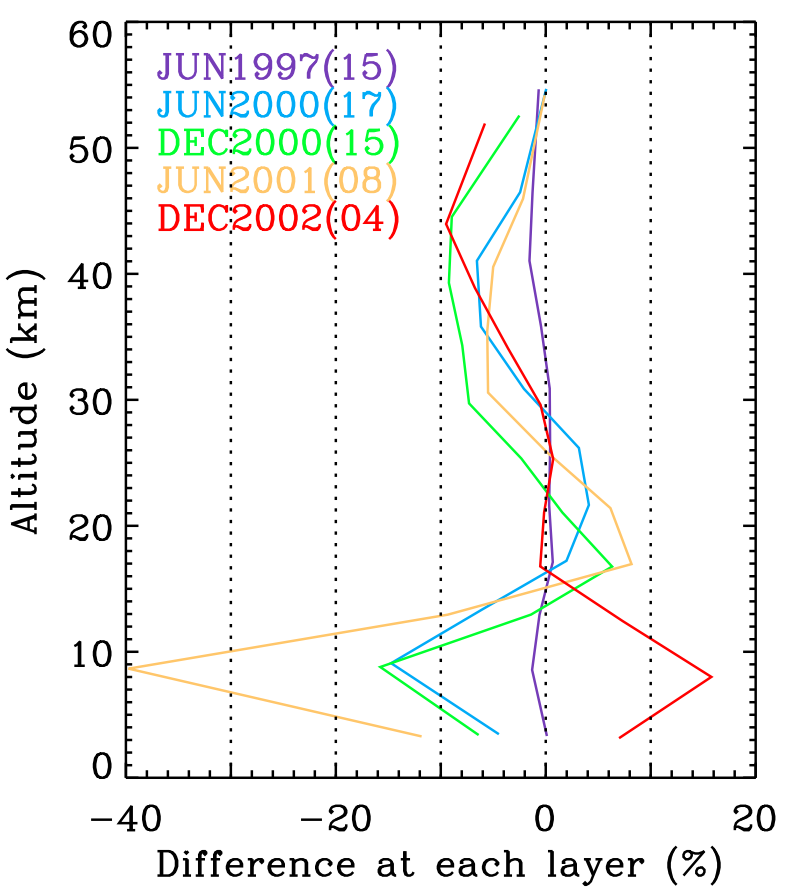

Fig. 3. Monthly mean percent differences in retrieved profiles ("without degradation correction" minus "with degradation correction") around Hohenpeißenberg for selected months shown in Fig. 2. The numbers in the brackets show the number of profiles within a month.

\section{The effect of degradation correction on ozone profile retrievals}

To show the effect of degradation on ozone profile retrievals spatiotemporally, we compare the retrievals with and without degradation correction from GOME measurements collocated $\left( \pm 1.5^{\circ}\right.$ latitude and $\pm 12.5^{\circ}$ longitude $)$ at Hohenpeißenberg $\left(11.0^{\circ} \mathrm{E}, 47.8^{\circ} \mathrm{N}\right)$ from 1996 through May 2003 and from an orbit of GOME measurements (i.e., as a function of latitude) on 15 July 2001. Figure 2 shows the differences in retrieved TO and TCO around Hohenpeißenberg. Our retrieval algorithm includes tropopause as a retrieval level (Liu et al., 2005), so that TCO is directly derived by summing up the partial column ozone in those tropospheric layers. The retrieval differences with and without the degradation correction are small during 1996-1999 due to insignificant degradation. Negative biases of up to $\sim 10 \mathrm{DU}$ ( $\sim 3 \%$ for TO and $\sim 30 \%$ for TCO) occur during 2000-2002, corresponding to the large reflectance degradation during this period. Note that the biases for TO and TCO peak at different times because of the wavelength dependence of the degradation. The retrievals return to normal in early 2002 and then show positive biases. Figure 3 illustrates the mean retrieval biases in ozone profiles for selected months near Hohenpeißenberg. After 2000, biases of up to $\sim 10 \%$ and $40 \%$ occur in the stratosphere and 

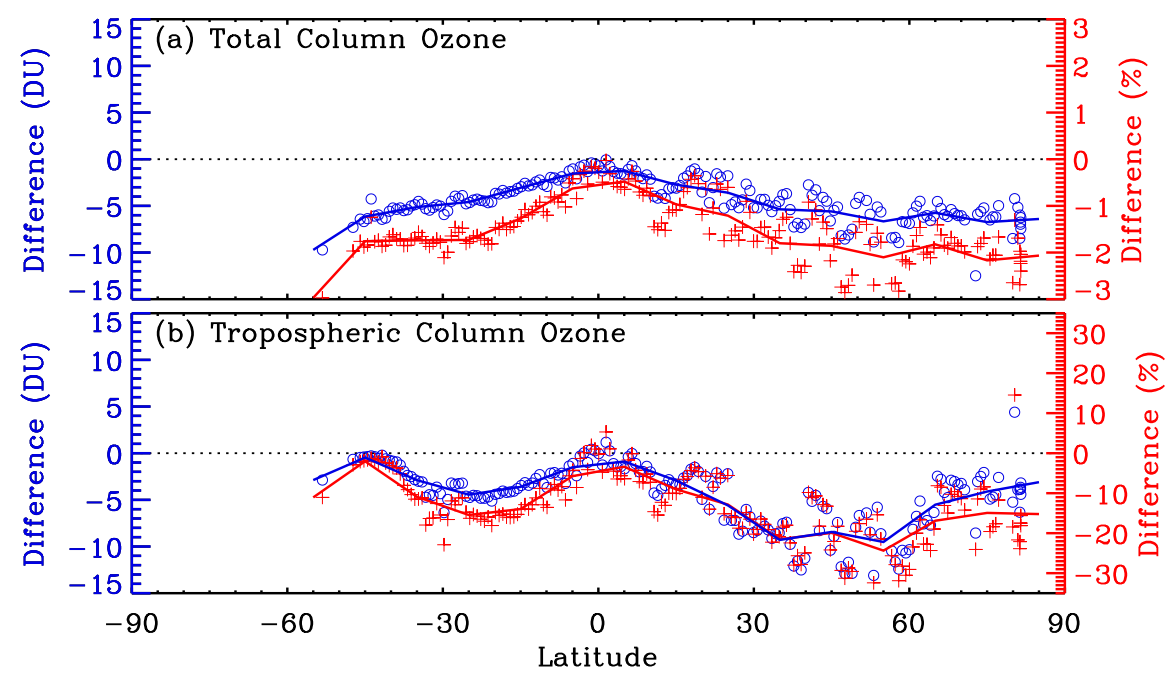

Fig. 4. As for Fig. 2, but for an orbit of GOME measurements on 15 July 2001 (orbit 10715173) as a function of latitude. The lines indicate the mean difference at every $10^{\circ}$-latitude band.

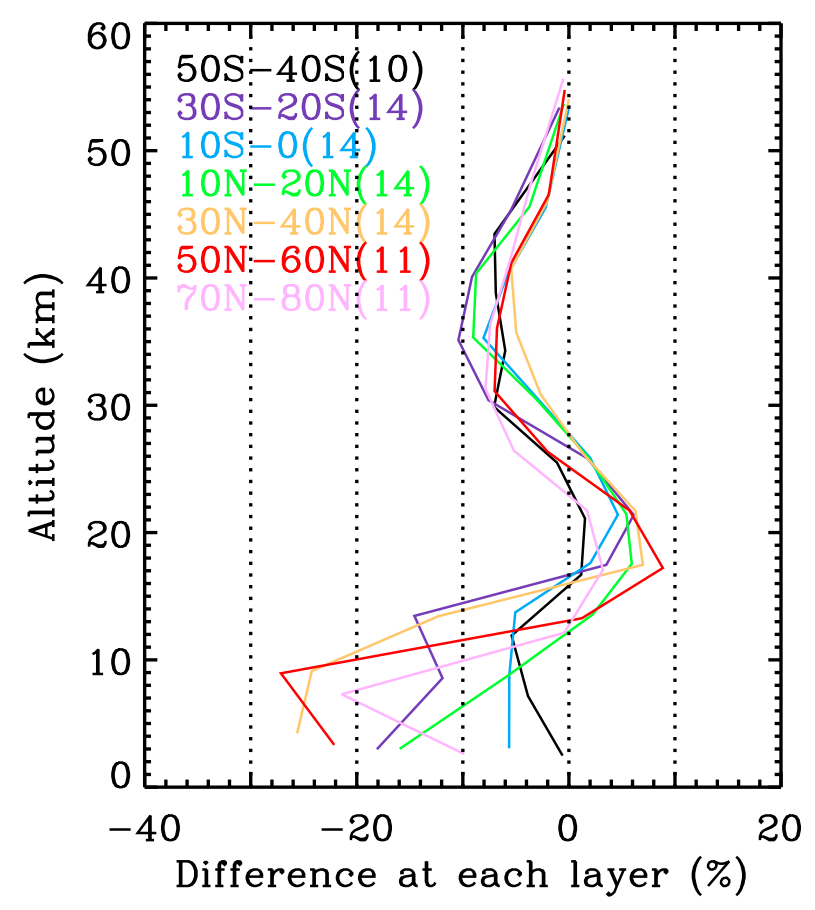

Fig. 5. As for Fig. 3, but for selected latitude ranges shown in Fig. 4. troposphere, respectively. Figure 4 shows the retrieval biases in TO and TCO for an orbit of GOME data in July 2001, when the TCO bias peaks at Hohenpeißenberg. The biases vary significantly with latitude, ranging from $\sim-10 \mathrm{DU}$ $(\sim-3 \%)$ to 0 DU in TO and from $\sim-14 \mathrm{DU}(\sim 33 \%)$ to $4 \mathrm{DU}$ $(\sim 10 \%)$ in TCO. The TO and TCO biases near the equator are small due to calibration features implemented in the algorithm. These calibrations are constrained by the derived total ozone from the Huggins bands and the a priori profile used. These constraints are probably stronger in the tropics, so less information is extracted from the measurements and retrievals are less sensitive to spectral biases. Around $60^{\circ} \mathrm{S}$ and north of $\sim 70^{\circ} \mathrm{N}$, the differences are much smaller in TCO, suggesting that the retrieved TCO is less sensitive to instrument degradation. This is because radiance measurements at larger solar zenith angles (i.e., higher latitudes) usually contain less ozone information in the troposphere. The profile biases can be up to $\sim-10 \%$ and $-30 \%$ in the stratosphere and troposphere, respectively (Fig. 5). Although large degradation occurs in channel 1a (Fig. 1), which is mainly sensitive to ozone in the stratosphere (up to $\sim 42 \mathrm{~km}$ in our retrieval algorithm), the degradation correction mainly changes retrievals in the troposphere (Figs. 3 and 5). This is because we apply a 2nd-order polynomial correction in 289-307 nm in the retrievals, which makes retrievals in the stratosphere less sensitive to degradation. For algorithms that do not use such on-line degradation correction features and do not perform empirical correction, the retrievals in the stratosphere would be much more sensitive to spectral biases as shown in Fig. 6b of Meijer et al. (2006).

Figures 6 and 7 illustrate the comparison of retrieved TO, TCO, and ozone profiles (with and without degradation correction) with collocated Dobson and ozonesonde 

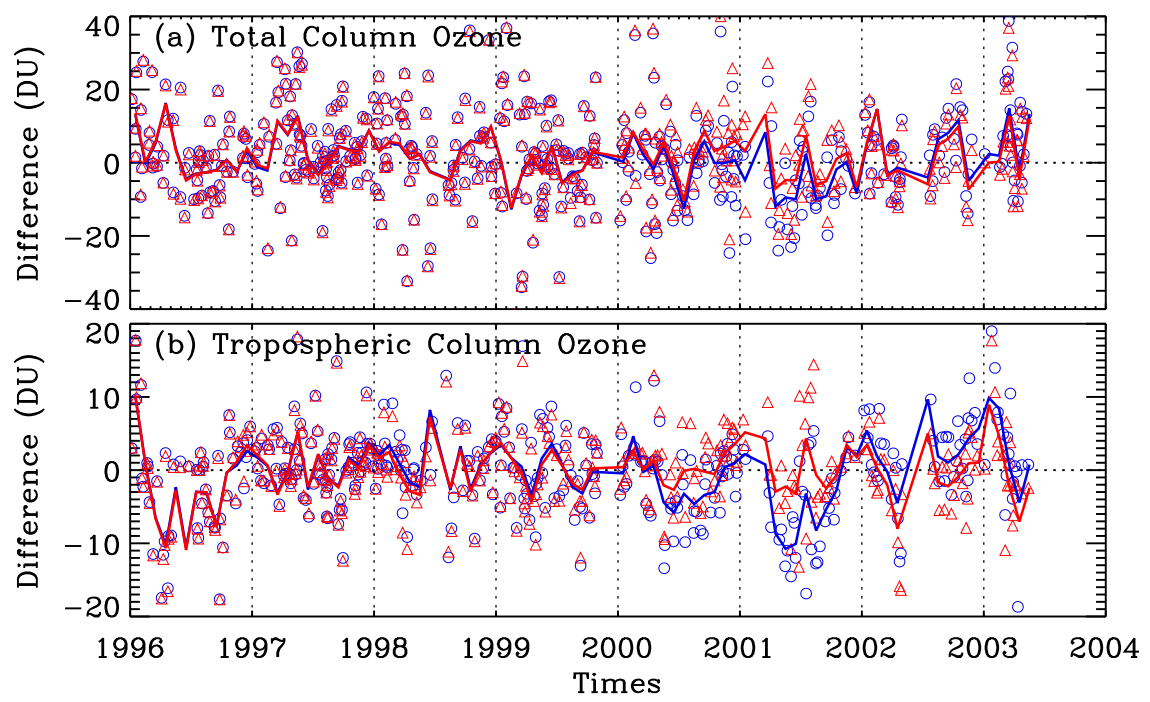

Fig. 6. (a) Differences between retrieved (blue/red: without/with degradation correction) and Dobson total column ozone at Hohenpeißenberg during 1996-May 2003. (b) Same as (a) but for comparisons with ozonesonde tropospheric column ozone.

measurements $\left( \pm 1.5^{\circ}\right.$ latitude, $\pm 8.0^{\circ}$ longitude, and $\left.\pm 8 \mathrm{~h}\right)$ at Hohenpeißenberg (archived at World Ozone and Ultraviolet Radiation Data Centre, ftp://ftp.tor.ec.gc.ca). Ozonesonde measurements are convolved with GOME retrieval averaging kernels and a priori ozone profiles to the GOME vertical resolution. This approach of transforming ozonesonde profiles in the intercomparison was first suggested by Connor et al. (1991). For the exact procedure one can refer to Liu et al. (2006). Ozonesonde TCO is integrated from the convolved profiles to reduce the smoothing from the stratosphere. Table 1 lists the statistics of comparing TO and TCO for retrievals without and with degradation correction in different time periods. For TO (Fig. 6a), the improvement with degradation correction is obvious during 2001; the negative biases was reduced by $\sim 4.5 \mathrm{DU}$. The bias with correction during 2000-2003 is more consistent with the 1996-2000 comparison. For TCO (Fig. 6b), we can clearly see substantial improvements, especially during 2000-2001; the biases and standard deviations are reduced and the correlation coefficients are improved. The bias since 2000 also shows better consistency with the comparison before 2000. Figure 7 shows that the profile biases during 2000-2002 were reduced by up to $30 \%$ and $10 \%$ in the troposphere and stratosphere, respectively, with the degradation correction. One exception occurs in December 2000, where the degradation correction increases the tropospheric biases. This is probably because the degradation offsets other systematic biases; note that retrievals in December 1997 show similar biases.

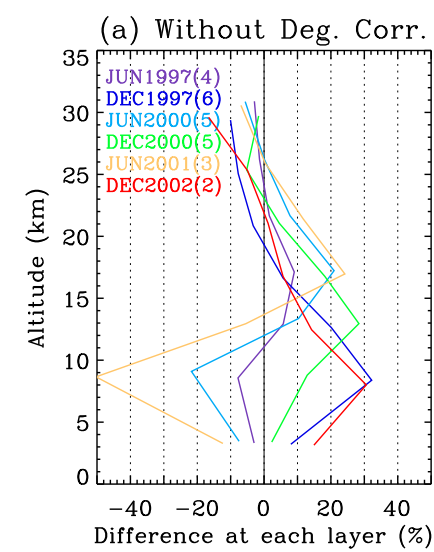

(b) With Deg. Corr.

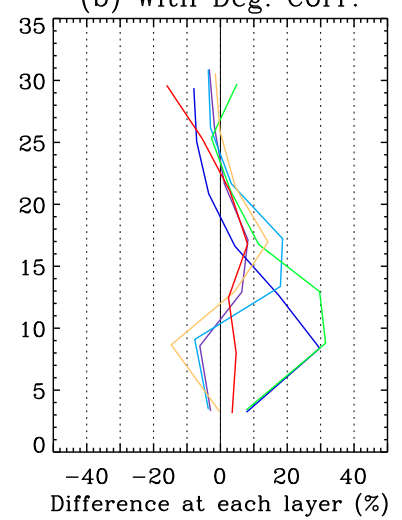

Fig. 7. Mean differences between retrieved and convolved ozonesonde ozone profiles at Hohenpeißenberg for selected months shown in Fig. 6. (a) Without degradation correction. (b) With degradation correction. The numbers in the brackets show the number of averaged profiles.

\section{Summary}

The degradation in GOME reflectance is derived from the ratio of average calibrated reflectance in $60^{\circ} \mathrm{N}-60^{\circ} \mathrm{S}$ to that in July-December 1995, with additional procedures to remove the dependence on solar zenith angle and seasonal variation and to reduce the dependence on atmospheric variability. This simple method does not need radiative transfer simulations with ozone observations or climatology and can be applied to the non-ozone absorbing wavelength range. Significant positive biases of up to $\sim 15-25 \%$ occur in the wavelength range $289-370 \mathrm{~nm}$ during $2000-2002$. The 
degradation varies significantly with wavelength and viewing zenith angle. The major features of the derived degradation are consistent with the physical understanding of how the thickness of contaminants on the scan mirror affects the radiances measured at different scan positions (Snel, 2000) and with derived degradation involving radiative transfer simulations with ozone observations and climatology (Krijger et al., 2005).

Without degradation correction, retrieval biases of up to $\sim 3 \%$ (10 DU), $30 \%$ (10 DU), $10 \%$, and $40 \%$ exist in total column ozone, tropospheric column ozone, stratospheric ozone and tropospheric ozone, respectively, from our GOME ozone profile retrieval algorithm (Liu et al., 2005), which features some on-the-fly radiometric calibrations to reduce the effect of degradation. We apply our new degradation correction to GOME measurements collocated around Hohenpeißenberg and demonstrate that this correction usually improves the retrievals relative to Dobson and ozonesonde measurements during 2000-2003 and improves the retrieval consistency during 1996-2003.

To further improve the accuracy of retrieved ozone profiles from the GOME record and fully utilize available information in GOME data, we need several major updates to our retrieval algorithm. The retrievals with our current degradation correction may be inadequate for trend analysis due to the underlying assumptions; a degradation correction scheme taking ozone trend into account would be more desirable. Our retrieval algorithm relies on on-line calibration corrections to reduce retrieval errors resulting from the initial calibration offset but at the cost of losing ozone information; systematic altitude-dependent retrieval biases still exist. This initial offset needs to be corrected for further retrievals. In addition, the algorithm requires further investigation into calibration problems in the spectral region $307-326 \mathrm{~nm}$, which is currently not used in our algorithm (Liu et al., 2005). Finally, GOME is a polarization-sensitive instrument and the polarization is derived from three (for GOME-1) broadband polarization measurement devices, which can lead to radiance errors of up to $10 \%$ (Schutgens and Stammes, 2003). The neglect of polarization in radiative transfer model simulation can lead to radiance errors of up to $10 \%$ in the ultraviolet (Mishchenko et al., 2003). We need to use a vector radiative transfer model to better account for errors in both GOME data and forward model simulations.

Acknowledgements. This study is supported by NASA and by the Smithsonian Institution. We acknowledge German Weather Service - Meteorological Observatory at Hohenpeißenberg and the Word Ozone and Ultraviolet Radiation Center for providing Dobson and ozonesonde measurements. We appreciate the ongoing cooperation of the European Space Agency and the German Aerospace Center in the GOME program. Finally, we thank the anonymous referees and Mark Weber for their constructive comments.

Edited by: A. Hofzumahaus

\section{References}

Chance, K. V., Burrows, J. P., Perner, D., and Schneider, W.: Satellite measurements of atmospheric ozone profiles, including tropospheric ozone, from ultraviolet/visible measurements in the nadir geometry: A potential method to retrieve tropospheric ozone, J. Quant. Spectrosc. Radiat. Transfer, 57(4), 467-476, 1997.

Connor, B.J., Parrish, A., and Tsou, J.-J.: Detection of stratospheric ozone trends by ground-based microwave observations, Proc. SPIE Int. Soc. Opt. Eng., 1491, 218-230, 1991.

ESA: The GOME users manual, European Space Agency (ESA) Publication SP-1182, ESA Publications Division, ESTEC, Noordwijk, The Netherlands, 1995.

Gupta, S. K., Stackhouse, P. W., Mikovitz, J. C., Cox, S. J. and Zhang, T.: Surface radiation budget over tropical pacific: Interannual variability, 12th Conference on Atmospheric Radiation, Madison, WI, USA, 2006.

Hasekamp, O. P. and Landgraf, J.: Ozone profile retrieval from backscattered ultraviolet radiances: The inverse problem solved by regularization, J. Geophys. Res., 106(D8), 8077-8088, 2001.

Hoogen, R., Rozanov, V. V., and Burrows, J. P.: Ozone profiles from GOME satellite data: Algorithm description and first validation, J. Geophys. Res., 104(D7), 8263-8280, 1999.

Krijger, J. M., Aben, I., and Landgraf, J.: CHEOPS-GOME: WP2.1: Study of instrument degradation, ESA SRONEOS/RP/05-018 Tech. rep., 2005.

Liu, X., Chance, K., Sioris, C. E., Spurr, R. J. D., Kurosu, T. P., Martin, R. V., and Newchurch, M. J.: Ozone profile and tropospheric ozone retrievals from Global Ozone Monitoring Experiment: Algorithm description and validation, J. Geophys. Res., 110(D20), D20307, doi:10.1029/2005JD006240, 2005.

Liu, X., Chance, K., Sioris, C. E., Kurosu, T. P., and Newchurch, M. J.: Intercomparison of GOME, ozonesonde, and SAGE-II measurements of ozone: Demonstration of the need to homogenize available ozonesonde datasets, J. Geophys. Res., J. Geophys. Res., 101 (D14), D114305, doi:10.1029/2005JD006718, 2006.

Meijer, Y. J., Swart, D. P. J., Baier, F., et al.: Evaluation of Global Ozone Monitoring Experiment (GOME) ozone profiles from nine different algorithms, J. Geophys. Res., 111 (D21), D21306, doi:10.1029/2005JD006778, 2006.

Mishchenko, M. I., Lacis, A. A. and Travis, L. D.: Errors induced by the neglect of polarization in radiance calculations for Rayleigh scattering atmospheres, J. Quant. Spectrosc. Radiat. Transfer, 51, 491-510, 1994.

Müller, M. D., Kaifel, A. K., Weber, M., Tellmann, S., Burrows, J. P., and Loyola, D.: Ozone profile retrieval from Global Ozone Monitoring Experiment (GOME) data using a neural network approach (neural network ozone retrieval system (NNORSY)), J. Geophys. Res., 108(D16), 4497, doi:10.1029/2002JD002784, 2003.

Munro, R., Siddans, R., Reburn, W. J., and Kerridge, B.: Direct measurement of tropospheric ozone from space, Nature, 392, 168-171, 1998.

Schutgens, N. A. J. and Stammes, P.: A novel approach to the polarization correction of spaceborne spectroscopy, J. Geophys. Res., 108 (D7), 4229, doi:10.1029/2002JD002736, 2003.

Snel, R.: In-orbit optical path degradation: GOME experience and SCIAMACHY prediction, ERS Envisat Symposium, SP-461, 
Göteborg, Sweden, 2000.

Tanzi, C. P., Snel, R., Hasekamp, O., and Aben, I.: Degradation of UV earth albedo observations by GOME, ERS-ENVISAT Symposium, SP-461,Göteborg, Sweden, 2000. van der A, R. J., van Oss, R. F., Piters, A. J. M., Fortuin, J. P. F., Meijer, Y. J., and Kelder, H. M.: Ozone profile retrieval from recalibrated GOME data, J. Geophys. Res., 107(D15), 4239, doi:10.1029/2001JD000696, 2002. 